\title{
Full Mouth Rehabilitation - The Enigma Continues
}

\author{
Anjali Giridhar Bhoyar¹, Seema Prakash Sathe ${ }^{2}$ \\ 1, 2 Department of Prosthodontics and Crown \& Bridge, Sharad Pawar Dental College and Hospital, \\ Wardha, Maharashtra, India.
}

\section{'Nothing Changes if Nothing Changes'}

Treating a case of full mouth rehabilitation has remained a challenge till date. Dentistry has witnessed many advancements in terms of material science, technology and treatment procedures. What has not evolved is the thought process of application of these newer methods and technology.

Any treatment procedure performed on a patient is not a straightforward mathematical calculation which can be implemented in a specified manner. Clinical processes, especially a case of full mouth rehabilitation requires comprehensive knowledge and understanding of the stomatognathic system.

The word rehabilitation in itself conveys responsibility. A lot is involved at both the ends - the receiver (patient) and the donor (the rehabilitation specialist). The oxford dictionary defines rehabilitation as 'The action of restoring someone to health or normal life through training and therapy after imprisonment, addiction, or illness.' It is a great responsibility on restoring dentist to bring the abnormal and compromised oral functions back on track.

The multidisciplinary dimension of the treatment cannot be ignored. Although the culmination of an elaborate treatment is by a restoring specialist which happens to be prosthodontist most of the time, other specialists such as endodontist, periodontist, oral surgeon, orthodontist and an oral radiologist play a significant role throughout the planning and execution. It is advisable to seek expert opinion and include specialty procedures whenever deemed necessary.

\author{
Corresponding Author: \\ Dr. Anjali Giridhar Bhoyar, \\ Department of Prosthodontics and Crown \& \\ Bridge, \\ Sharad Pawar Dental College and Hospital, \\ Wardha, Maharashtra, India. \\ E-mail: dranjaliborle@gmail.com
}

DOI: $10.14260 / \mathrm{jemds} / 2021 / 732$

How to Cite This Article:

Bhoyar AG, Sathe SP. Full mouth rehabilitation - the enigma continues. $J$ Evolution Med Dent Sci 2021;10(41):36103611, DOI: 10.14260/jemds/2021/732

Submission 02-08-2021,

Peer Review 22-09-2021,

Acceptance 28-09-2021,

Published 11-10-2021.

Copyright (C) 2021 Anjali Giridhar Bhoyar et al. This is an open access article distributed under Creative Commons Attribution License [Attribution 4.0 International (CC BY 4.0)] 
As an academician, when I see post graduate students approaching a case of full mouth rehabilitation, I find them lost in the web of information, standing at a crossroad, unsure of the planning and execution. The literature review provides us information on certain philosophies, strategies and methodology of treating a case of full mouth rehabilitation. . $^{2-8}$ However, the students take up a novel approach. If they are left to plan an unguided case, few published case reports are referred and a treatment plan is formulated and presented without understanding the WHAT, WHEN, WHY and HOW! Hence a $360^{\circ}$ knowledge of complete stomatognathic system and restorative science is must as a post graduate student so that such treatments are rendered effectively at the practice level independently.

Comprehensive treatment of the patient with visualization of final result to improve the oral and general health, masticatory function and aesthetics must be the ultimate goal.

'Change can either challenge or threaten us. Your beliefs pave your way to success or block you.' - Marsha Sinetar

Financial or other competing interests: None.

Disclosure forms provided by the authors are available with the full text of this article at jemds.com.

\section{REFERENCES}

[1] https://www.lexico.com/definition/rehabilitation accessed on 14th Sep 2021

[2] Goldman I. The goal of full mouth rehabilitation. J Prosth Dent 1952;2(2):246-51.

[3] Binkley TK, Binkley CJ. A practical approach to full mouth rehabilitation. J Prosthet Dent 1987;57:261-6.

[4] Baid GC, Lakshman SD, Marilingiah A, et al. Comprehensive treatment of compromised dentition: an interdisciplinary approach. J Interdiscip Dent 2012;2(3):205-10.

[5] Banerjee S, Chakraborty N, Singh R, et al. Full-mouth rehabilitation of a patient with severe attrition using the Hobo twin-stage procedure. Contemp Clin Dent 2012;3(1):103-7.

[6] Tiwari B, Ladha K, Lalit A, et al. Occlusal concepts in full mouth rehabilitation: an overview. J Indian Prosthodont Soc 2014;14(4):344-51.

[7] Parmar A, Choukse V, Palekar U, et al. An appraisal on occlusal philosophies in full mouth rehabilitation: a literature review. Int J Prosthodont Restorative Dent 2016;6(4):89-92.

[8] Devassy JP, Sivadas A, Muhammed S. Full mouth occlusal rehabilitation: by Pankey Mann Schuyler philosophy. IP Ann Prosthodont Restor Dent 2017;3(1):29-33. 